Vol 14, Issue 11, 2021

\title{
COMPARISON OF POST-OPERATIVE VALUES WITH PRE OPERATIVE VALUES OF CA 15-3 AND ITS PROGNOSTIC VALUE
}

\author{
CHAHAT SEHGAL ${ }^{1}$, SEEMA $^{1 *}{ }^{*}$, MANINDER KAUR $^{1}$, ASHWANI KUMAR $^{2}$ \\ ${ }^{1}$ Department of Biochemistry, Government Medical College and Rajindra Hospital, Patiala, Punjab, India. ${ }^{2}$ Department of Surgery, \\ Government Medical College and Rajindra Hospital, Patiala, Punjab, India. Email: seemanaurath@gmail.com
}

Received: 25 August 2021, Revised and Accepted: 05 October 2021

\section{ABSTRACT}

Objective: This study was designed and conducted to establish the relationship of biomarker CA 15-3 levels with tumor load in cases of carcinoma breast.

Methods: Fifty female patients with confirmed diagnosis of breast malignancy were included in the study. CA 15-3 levels were measured before surgery and after surgery.

Results: It was found that levels of the biomarker were increased in all the cases; the rise was higher in advance cases of carcinoma. Levels decreased after the surgery and this decrease was statistically significant.

Conclusions: It was concluded that levels of CA 15-3 increase in cases of carcinoma breast; higher levels indicate advanced stage and that decrease in levels indicate effective treatment.

Keywords: Carcinoma breast, CA 15-3, Effective treatment, Tumor load.

(C) 2021 The Authors. Published by Innovare Academic Sciences Pvt Ltd. This is an open access article under the CC BY license (http://creativecommons.org/ licenses/by/4.0/) DOI: http://dx.doi.org/10.22159/ajpcr.2021v14i11.43078. Journal homepage: https://innovareacademics.in/journals/index.php/ajpcr

\section{INTRODUCTION}

Mankind has been trying to decipher the enigma of most dreaded diagnosis, malignancy. Lots of headway has been made in the field of detection and diagnosis. Definitive treatment of malignancy still remains elusive. Concerted efforts have been made to understand incidence and distribution of various malignancies, worldwide, and region wise.

As of 2020, female breast cancer has become most commonly diagnosed malignancy, a spot which was earlier occupied by lung cancer [1]. As per National Cancer Registry Programme India report of 2020, breast cancer is the most commonly diagnosed malignancy in India [2].

Staging of malignancies have been traditionally done using TNM system. American Joint Committee on Cancer has stressed on the importance of biomarkers and has included biomarkers in the staging in its eighth edition. Biomarkers have been integrated with anatomic definitions [3].

Biomarkers for tumors are found in body tissues such as blood and urine. They are either produced by the tumor cells or by the body cells in response to the proliferating tumor. Levels of biomarkers increase in the presence of malignancies [4]. Biomarker levels are useful in evaluating the efficacy of chemotherapy, radiotherapy or surgery, and the subsequent disease progression [5].

CA 15-3 has been acknowledged as one of the first circulating factors with prognostic value for breast cancer. Monitoring of CA 15-3 can be useful to evaluate therapy in patients with advanced breast cancer which is not assessable clinically or by radiological procedures [6]. Clinical utility of CA 15-3 has been established with evidence and is recommended for use in practice [7]. It is also useful in monitoring response to therapy [8].

Aim

CA 15-3 has been established as biomarker of diagnostic value in breast cancer, as well as to evaluate the response to various treatment modalities. To further establish role of CA 15-3 in assessing response to treatment, it was decided to compare pre op levels of CA 15-3 with postoperative levels. Surgery is the surest technique to reduce tumor load of the body, by removal of primary tumor as well as sentinel lymph nodes.

\section{MATERIALS AND METHODS}

Fifty female patients with confirmed diagnosis of carcinoma breast were included in the study. These patients were scheduled to undergo surgery for removal of primary tumor and axillary clearance of lymph nodes. Patients were explained the study and consent was obtained. Patients with history of other malignancies apart from carcinoma breast and those with liver disease were excluded from the study. Serum values of CA 15-3 were determined in these patients before and after the surgery. Pre-operative and post-operative serum levels of CA 15-3 were compared statistically using paired t-test in SPSS software.

\section{OBSERVATION AND RESULTS}

Age-wise distribution of patients included in the study $(n=50)$ is shown in Table1.

Breast cancer has been diagnosed in almost every age group of adult females. In the present study, maximum number of patients was in the age group of 41-50 years.

Patients were grouped as per the staging of breast cancer. Stage-wise distribution of patients is shown in Table 2 .

$52 \%$ of the cases $(n=26)$ were in Stage III of the disease. Mean preoperative levels of serum CA 15-3 in various stage groups of the disease are depicted in Table 3.

Mean values of CA 15-3 increased with advancing stage of the disease. It was minimum in Stage I cases and maximum in Stage III patients. Comparison and statistical analysis of pre-operative and post-operative levels of CA 15-3 is shown in Table 4. 
Table 1: Age-wise distribution

\begin{tabular}{lll}
\hline Age Group & Frequency & Percentage \\
\hline$<41$ & 15 & 30 \\
$41-50$ & 16 & 32 \\
$51-60$ & 10 & 20 \\
$61-70$ & 4 & 8 \\
$>70$ & 5 & 10 \\
Total & 50 & 100 \\
\hline
\end{tabular}

Table 2: Distribution of patients as per stage of carcinoma

\begin{tabular}{lll}
\hline Stage & Frequency & Percentage \\
\hline I & 4 & 8 \\
II & 20 & 40 \\
III & 26 & 52 \\
Total & 50 & 100 \\
\hline
\end{tabular}

Table 3: CA 15-3 Mean pre-operative levels in different stage groups

\begin{tabular}{ll}
\hline Stage & Mean \pm SD \\
\hline I & $32.39 \pm 1.99$ \\
II & $52 \pm 11.96$ \\
III & $71.77 \pm 25.99$ \\
\hline
\end{tabular}

Table 4: Comparison of Pre-operative and Post-operative Levels of CA 15-3

\begin{tabular}{lllll}
\hline Levels & Mean \pm SD & t-value & p-value & Significance \\
\hline Pre-operative & $60.49 \pm 23.6$ & 11.97 & $<0.0001$ & Extremely \\
Post-operative & $16.88 \pm 10.34$ & & & Significant \\
\hline
\end{tabular}

There was statistically significant decrease in mean CA 15-3 levels in the post-operative period where tumor load was decreased surgically.

\section{DISCUSSION}

The present study was conducted at Government Medical College and Rajindra Hospital Patiala, India. This study has established that serum levels of CA 15-3 increase in cases of carcinoma breast. The rise in levels of the biomarker corresponds with the stage of disease, higher levels are found in more advanced stages. Levels decreased significantly after surgical reduction of tumor mass.

Hashim in his study concluded that levels of CA 15-3 levels increase in cases of carcinoma breast. This increase is directly related to advancing stage of disease. Level of CA 15-3 can be used as prognostic tool as high levels indicate advanced stage [9]. Findings of the present study are also on the same lines. Levels were increased in patients of carcinoma breast. Levels increased with advancing stage.

Fejzic et al. conducted a study CA 15-3 levels in cases of breast cancer and compared the levels between cases with and without metastases [10]. They found significant correlation between CA 15-3 levels and presence of metastases and dissemination of disease. Biomarker levels were also found to be higher in patients of Stage III in the present study. Khan et al. compared levels of CA 15-3 in patients of breast cancer, before and after surgery [11]. Levels decreased significantly after the surgery. They suggested that post-operative levels compared to pre-operative levels, can be an important tool. If the post-operative levels increase, it indicates recurrence. Findings of the present study are also on the same lines. CA 15-3 levels decreased significantly after surgery.

Gupta et al. in their study on prognostic value of CA 15-3 in breast cancer noted that the post-treatment levels were significantly lower than pre-treatment levels [12]. They also concluded that higher levels are associated with poor prognosis. These findings are in concurrence with the findings of present study. Elevated pre-treatment levels indicate disseminated disease.

Khushk et al. in their study concluded that post-operative value of CA 15-3 significantly decreased after surgery [13]. Comparison of pre- and post-operative levels may determine the prognosis and can help in formulating optimal patient care regime. Results of the present study concur with this study. Popat et al. in their study concluded that CA $15-3$ is an important prognostic tool and is important for measuring therapeutic efficacy in breast cancer cases [14]. Findings of the present study agree with this study.

\section{CONCLUSIONS}

Role of biomarkers in staging of malignancy has been accepted and is being widely used. New markers are being identified and evaluated clinically. CA 13-5 has been identified as an important biomarker in cases of breast carcinoma. Levels of CA 15-3 have been included in TNM staging of malignancy of breast. The levels correlate very well with tumor load and metastases. Efficacy of treatment can be evaluated by measuring serial serum levels of this biomarker. Initial higher levels or increasing levels despite treatment indicate poor prognosis.

\section{ACKNOWLEDGMENTS}

None.

\section{CONFLICT OF INTEREST/FUNDING}

None.

\section{REFERENCES}

1. Sung H, Ferlay J, Siegel RL, Laversanne M, Soerjomataram I, Jemal AA, et al. Global cancer statistics 2020: GLOBOCAN estimates of incidence and mortality worldwide for 36 cancers in 185 countries. CA Cancer J Clin 2021;71:209-49.

2. Mathur P, Sathishkumar K, Chaturvedi M, Das P, Sudarshan KL, Santhappan S, et al. Cancer statistics 2020: Report from national cancer registry programme, India. JCO Global Oncol 2020;6:1063-75.

3. Hortobagyi GN, Edge SB, Giuliano A. New and important changes in the TNM staging system for breast cancer. Am Soc Clin Oncol Educ Book 2018;38:457-67.

4. Kilpatrick ES, Lind MJ. Appropriate requesting of serum tumour markers. BMJ 2009;339:b3111.

5. Amayo AA, Kuria JG. Clinical application of tumour markers: A review. East Afr Med J 2009;86 Suppl 12:S76-83

6. Duffy JM. Serum tumor markers in breast cancer: Are they of clinical value? Clin Chem 2006;52:345-51.

7. Maric P, Ozretic P, Levanat S, Oreskovic S, Antunac K, BeketicOreskovic L. Tumor markers in breast cancereevaluation of their clinical usefulness. Coll Antropol 2011;35:241-7.

8. Kabel AM. Tumor markers of breast cancer: New prospectives. J Oncol Sci 2017;3:5-11.

9. Hashim ZM. The significance of CA 15-3 in breast cancer patients and its relationship to HER-2 receptor status. Int J Immunopathol Pharmacol 2014:27:45-51

10. Fejzic H, Mujagic S, Azabagic S, Burina M. Tumor marker CA 15-3 in breast cancer patients. Acta Med Acad 2015;44:39-46.

11. Khan MA, Trivedi HP, Atara AN. Analysis of tumour marker CA 15-3 in breast cancer following surgery. Int Surg J 2016;3:1491-4.

12. Gupta SK, Kumar V, Anees A, Goel A. The study of prognostic significance of CA 15-3 in breast cancer. Int Surg J 2018;5:580-3.

13. Khushk M, Khan A, Rehman A, Sheraz S, Tunio YM, Rehman K, et al. The role of tumor markers: Carcinoembryonic antigen and cancer antigen 15-3 in patients with breast cancer. Cureus 2021;13:e16298.

14. Popat VC, Mehta SG, Dave N. Evaluation of diagnostic and prognostic role of serum tumour marker CA $15-3$ in breast malignancy a retrospective study with the use of $3^{\text {rd }}$ generation ELISA. Indian J Appl Res 2021;11:21-2. 